\title{
"Killing two birds with one stone": endoscopic management of PUJ and VUJ obstructions with a renal stone in a congenital solitary kidney
}

\author{
C Christofides, ${ }^{1,2}$ (D) M Carides, ${ }^{3,4}$ (D) A Adam, ${ }^{1,2,4}$ (D) \\ ${ }^{1}$ Department of Urology, Helen Joseph Hospital, South Africa \\ ${ }^{2}$ Division of Urology, Department of Surgery, Faculty of Health Sciences, University of the Witwatersrand, South Africa \\ ${ }^{3}$ Outpatient Department, Bertha Gxowa Hospital, South Africa \\ ${ }^{4}$ Wits Donald Gordon Medical Centre, South Africa
}

Corresponding author, email: c.chris@live.co.za

\begin{abstract}
Summary
We report on the diagnosis and management of a 25 -year-old female with a congenital solitary kidney associated with simultaneous pelviureteric (PUJ) and vesicoureteric (VUJ) junction obstructions complicated by a lower pole renal stone. The patient was successfully managed completely endoluminally over two procedures with the use of double-J stents and a laser fibre to incise the VUJ and perform endopyelotomy at the PUJ followed by extraction of the stone. This case demonstrates the efficacy and minimal invasive endoscopic urological surgery even in the face of numerous pathologies, which traditionally required more invasive procedures.
\end{abstract}

Keywords: solitary kidney, pelviureteric junction obstruction, vesicoureteric junction obstruction, renal calculus, endoscopy

\section{Case report}

A 25-year-old female presented to the urology outpatient department complaining of occasional right flank pain and recurrent urinary tract infections which had been treated with repeated courses of antibiotics. She had no past medical or surgical history and one previous uneventful pregnancy with a normal vaginal delivery. The only significant finding was some mild renal angle tenderness on the right side.

Blood and urine sent to the laboratory showed normal renal function and microscopic haematuria but no evidence of current urinary tract infection as well as negative urinary tuberculosis (TB) cultures. Abdominal ultrasound showed a right-sided hydronephrosis and an absent left kidney. The patient was then sent for a non-contrast kidney, ureter and bladder (KUB) CT which revealed right-sided severe hydronephrosis and hydroureter with a non-obstructing $10 \mathrm{~mm}$ calculus in the lower pole calyx but no ureteric calculi with no evidence of prior urogenital TB or schistosomiasis. The absence of the left kidney was confirmed. The remainder of the scan was normal.

The patient was counselled about the various surgical approaches: open, laparoscopic, percutaneous and endoluminal. She consented for all options as it was difficult to advise her preoperatively whether the less invasive options would be effective or definitive. The patient expressed concern about the cosmetic appearance of open surgery and preferred to avoid scars. Therefore, a minimally invasive endoluminal approach was undertaken.
In theatre, an on-table cystogram revealed a normally shaped bladder without vesicoureteric reflux. Cystoscopy found a normal urethra and bladder but abnormal ureteric orifices. There was absence of the left ureteric orifice, which was in keeping with the congenital renal agenesis, and the right ureteric orifice and intramural ureter were very tight, making it difficult to pass a guidewire then ureteric catheter. Right retrograde studies (Figure 1) demonstrated hydronephrosis and hydroureter with "beaking" of contrast at both the pelviureteric (PUJ) and vesicoureteric (VUJ) junctions suggestive of ureteric obstruction at two sites. A filling defect due to a renal calculus in a lower pole calyx was noted.

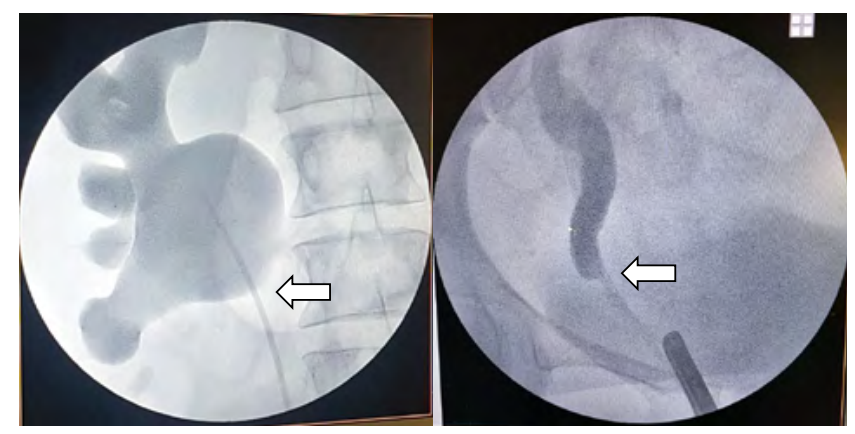

Figure 1: Retrograde studies showing hydronephrosis secondary to pelviureteric junction obstruction (left) and hydroureter secondary to vesicoureteric obstruction (right) 

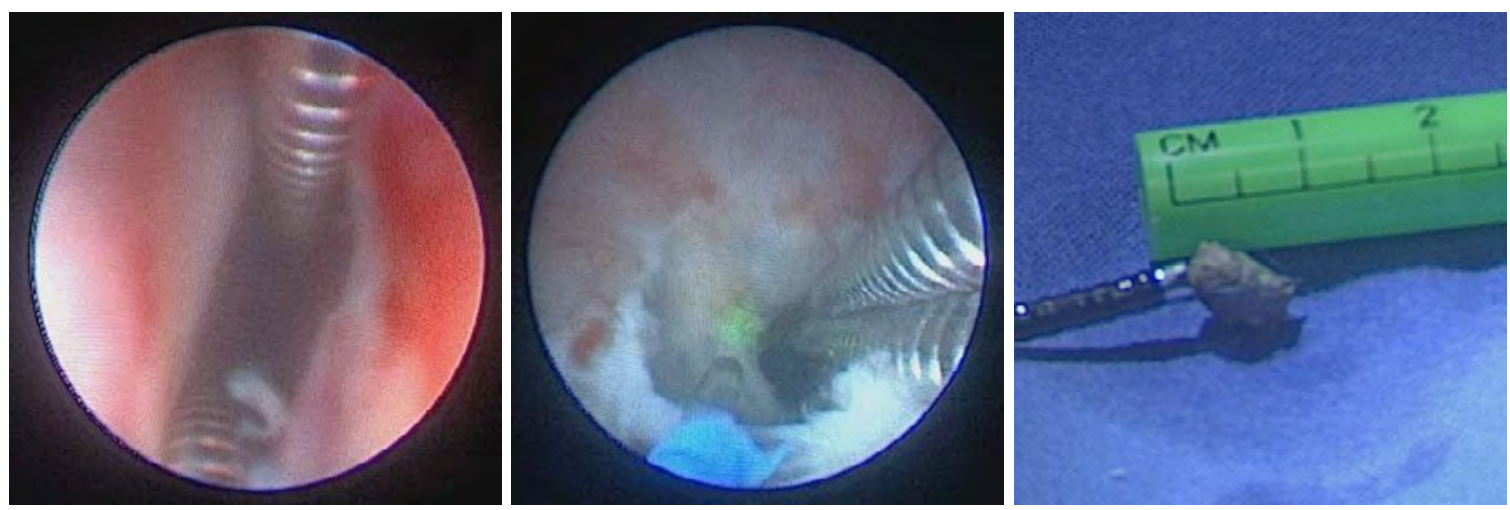

Figure 2: Endoscopic images of the pelviureteric obstruction being splayed open with two guidewires followed by endopyelotomy using a laser fibre. The lower pole renal stone was then extracted using a stone basket.

At this procedure, two guidewires were passed into the right ureteric orifice then a laser fibre was used to splay open the VUJ obstruction. Two Bard double-J stents $26 \mathrm{~cm} / 6 \mathrm{~F}$ were placed to allow for healing and to ensure good patency at the lasered VUJ. A month later, a second procedure was performed. It was noted that the previously lasered VUJ was widely patent. The PUJ obstruction was visualised with a rigid ureteroscopy and was dealt with in a similar manner to the VUJ. Two guidewires spread the tight PUJ and a laser fibre endopyelotomy was done in a posterolateral direction (Figure 2). This enabled flexible ureteroscopy to locate, capture and remove the lower pole renal calculus intact, through the widened PUJ and VUJ (Figure 2).

The patient recovered from both procedures without any early complications and returned for stent removal six weeks later. A MAG3 renogram was done a month after DJ stent removal and showed that there was an adequately functioning right kidney, with good overall drainage $(60 \%$ of peak activity drained from the renal pelvis by the end of the dynamic phase and bladder activity noted from 5 minutes). She has been followed up regularly with normal renal function and improvement in the severity of the hydronephrosis on sonar from her preoperative baseline. The patient has been counselled about having a single kidney and will continue to come for follow-up visits in the future.

\section{Discussion}

This patient had a multitude of urological pathologies for which there are a variety of management options. This case illustrates that it is important to consider all pathologies in a holistic manner rather than managing each in isolation. This patient had two sites of ureteric narrowing (PUJ and VUJ) and one lower pole renal stone in the setting of a single kidney in a young healthy female patient.

A patient can be considered to have a solitary kidney in a variety of scenarios, including congenital, previous unilateral nephrectomy or in the presence of a non-functioning kidney on one side. ${ }^{1}$ This patient has congenital absence of the left kidney, most likely due to renal agenesis which occurs in 1 in 1200 live births. ${ }^{2}$ Unilateral renal agenesis often goes undiagnosed in most patients but can be associated with ipsilateral urogenital abnormalities as in this case. ${ }^{1,2}$ The condition is also associated with an increased risk of chronic kidney disease and may require lifetime monitoring with early intervention for any problems. ${ }^{1,2}$
Simultaneous congenital VUJ and PUJ obstructions are very rare and often this dual diagnosis can be overlooked on initial work-up in $54.5 \%$ to $78.6 \%$ in different series. ${ }^{3-5}$ Varying degrees of obstruction at both ends of the ureter can result in different radiological findings, while severe obstruction of one end can completely mask the other obstruction. ${ }^{5}$ PUJ obstruction is usually more readily recognised than the VUJ obstruction. ${ }^{3,4}$ The VUJ obstruction may only be picked up if retrograde studies are done in theatre or if specifically looked for on contrast-enhanced imaging with a high index of suspicion. ${ }^{3,4}$ In some cases, dual obstruction is only diagnosed after repair of one obstruction has been performed, but the persistent drainage issues can lead to infections and other complications in the postoperative period and further compromise renal function. ${ }^{3,5}$ Fortunately, in this case, the presence of hydroureter on CT scan alerted us to the fact that there was a distal ureteric issue as well, which prompted us to perform retrograde studies during the first procedure, thus clearly demonstrating the VUJ and PUJ obstructions (Figure $1)$.

Historically, both VUJ and PUJ obstructions were managed with open or laparoscopic procedures rather than endoluminally as they have more durable results. ${ }^{6,7}$ However, technical improvements, such as endoscope miniaturisation, improved deflection mechanisms, enhanced optical quality and more effective accessories, have led to an increased efficacy of the endoluminal approach and its consideration as first line management. ${ }^{6-8}$

Lower pole renal stones can be managed either endoluminally with ureterorenoscopy and laser lithotripsy or by percutaneous nephrolithotomy (PCNL). ${ }^{9}$ Extracorporeal shockwave lithotripsy is generally reserved for smaller stones in this position. ${ }^{9}$ PCNL is associated with higher stone-free rates than ureterorenoscopy, but at the expense of higher complication rates, blood loss and admission times. ${ }^{10}$

Based on the benefits of quick recovery, minimal renal damage and no scarring, we decided in conjunction with the patient, to try and manage all the issues by a staged endoluminal approach rather than to go for a more invasive single stage procedure. Fortunately, we managed, at least in the short term, to resolve the VUJ and PUJ obstructions and remove the renal stone.

This case demonstrates the feasibility and minimal invasiveness of endoscopic urological surgery even in the face of numerous pathologies in the difficult setting of a solitary kidney. We believe this approach may be definitive 
and does not increase the risk of more invasive surgical procedures should they be necessary in the future.

\section{Conflict of interest}

The authors declare no conflict of interest.

\section{Ethical approval}

Ethics clearance was obtained from the Human Research Ethics Committee of the University of the Witwatersrand, Johannesburg. Ethics number: M2011146

\section{ORCID}

C Christofides (iD https://orcid.org/0000-0003-0330-2963

M Carides (iD https://orcid.org/0000-0003-1428-9493

A Adam (iD https://orcid.org/0000-0001-9069-3282

\section{REFERENCES}

1. Godron-Dubrasquet A, Didailler C, Harambat J, Llanas B. Solitary kidney - management and outcome. Arch Pediatr. 2017;24(11):1158-63. https://doi.org/10.1016/j. arcped.2017.08.016.

2. Shapiro E, Telegrafi S. Anomalies of the upper urinary tract. In: Wein A, Kavousi LR, Partin AW, Peters CA. CampbellWalsh, editors. Urology. 11th ed. Philadelphia: Elsevier; 2016. p. 2980

3. Halder P, Shukla RM, Mandal KC, Mukhopadhyay B, Barman S. Double obstruction of ureter - a diagnostic challenge. J Indian Assoc Pediatr Surg. 2014;19(3):129-32. https://doi. org/10.4103/0971-9261.136457.
4. Lee YS, Im YJ, Lee $\mathrm{H}$, et al. Coexisting ureteropelvic junction obstruction and ureterovesical junction obstruction - is pyeloplasty always the preferred initial surgery? Urology. 2014;83(2):443-9. https://doi.org/10.1016/j. urology.2013.08.087.

5. Cay A, Imamoglu M, Bahat E, Sarihan H. Diagnostic difficulties in children with coexisting pelvi-ureteric and vesico-ureteric junction obstruction. BJU Int. 2006;98(1):17782. https://doi.org/10.1111/j.1464-410X.2006.06187.x.

6. Arrabal-Martín M, Zuluaga-Gómez A, Merino-Salas S, Nogueras-Ocaña M, Arrabal-Polo MÁ. Endoscopic treatment of ureterovesical junction obstructive pathology-a description of the oblique meatotomy technique and results. Can Urol Assoc J. 2013;7(11-12):E728-31. https://doi.org/10.5489/ cuaj. 496.

7. Jacobs BL, Lai JC, Seelam R, et al. Urologic Diseases in America Project. The comparative effectiveness of treatments for ureteropelvic junction obstruction. Urology. 2018;111:727. https://doi.org/10.1016/j.urology.2017.09.002.

8. Auge BK, Dahm P, Wu NZ, Preminger GM. Ureteroscopic management of lower-pole renal calculi - technique of calculus displacement. J Endourol. 2001;15(8):835-8. https:// doi.org/10.1089/089277901753205852.

9. Türk C, Neisius A, Petrik A, Seitz C, Skolarikos A, Thomas $\mathrm{K}$; members of the EAU Urolithiasis Guidelines Panel. EAU Guidelines on Urolithiasis. Edn. presented at the EAU Annual Congress Amsterdam; 2020. ISBN 978-94-92671-07-3.

10. De S, Autorino R, Kim FJ, et al. Percutaneous nephrolithotomy versus retrograde intrarenal surgery - a systematic review and meta-analysis. Eur Urol. 2015;67(1):125-37. https://doi. org/10.1016/j.eururo.2014.07.003. 